\title{
Amyloid precursor protein-mediated modulation of capacitive calcium entry
}

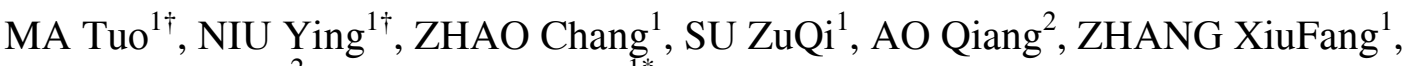 \\ ZHAO NanMing ${ }^{2} \&$ GONG YanDao ${ }^{1 *}$ \\ ${ }^{1}$ State Key Laboratory of Biomembrane and Membrane Biotechnology, School of Life Sciences, Tsinghua University, Beijing 100084, China; \\ ${ }^{2}$ Institute of Neurological Disorders, Yuquan Hospital, Tsinghua University, Beijing 100084, China
}

Received May 23, 2012; accepted September 29, 2012

\begin{abstract}
Alzheimer's disease (AD) is a progressive neurodegenerative disorder. In the present study, the function of amyloid precursor protein (APP) in modulating capacitive calcium entry (CCE), a refilling mechanism for depleted intracellular calcium stores, was investigated. CCE in neural 2a (N2a) cells stably expressing wild-type human APP was lower than in wild-type N2a cells, while CCE in APP knockout mouse embryonic fibroblast (MEF) cells was higher than in their wild-type counterparts. We demonstrate that wild-type APP depresses CCE. Furthermore, using N2a cells transfected with C-terminal APP fragments, we show that these fragments anchored in the cell membrane play an important role in CCE depression.
\end{abstract}

Alzheimer's disease, amyloid precursor protein, capacitive calcium entry

Citation: $\quad$ Ma T, Niu Y, Zhao C, et al. Amyloid precursor protein-mediated modulation of capacitive calcium entry. Chin Sci Bull, 2012, 57: 4552-4559, doi: $10.1007 /$ s11434-012-5526-Z

Amyloid precursor protein (APP) plays an important role in the pathophysiology of Alzheimer's disease (AD), one of the most common neurodegenerative diseases affecting an increasing population worldwide [1,2]. APP can be processed to generate proteolytic fragments through two distinct intracellular metabolic pathways. One is the nonamyloidogenic pathway, through which APP is cleaved by $\alpha$-secretase, generating a large extracellular soluble APP $\alpha$ $(\mathrm{AAP} \alpha)$ and an intracellular C-terminal fragment (C83). The other is the amyloidogenic pathway, where APP is sequentially cleaved by $\beta$ - and $\gamma$-secretase. $\beta$-Secretase cleavage produces extracellular soluble APP $\beta$ (sAPP $\beta$ ) and C99 fragments. The C99 fragment is further cleaved by $\gamma$-secretase to liberate the amyloid intracellular domain (AICD) and $\beta$-amyloid peptide (A $\beta)$, which is deposited to form senile plaques in $\mathrm{AD}$ brains $[1,3]$.

APP gene mutations have long been known to be major causes of the familial form of $\mathrm{AD}$, and have attracted exten-

$\dagger$ These authors contributed equally to this work.

*Corresponding author (email: gongyd@tsinghua.edu.cn) sive study [4,5]. Although the relationship between APP mutations and $\mathrm{AD}$ is already well established, the normal physiological functions of APP are still unclear. An increasing body of evidence suggests that APP might be involved in various cellular activities, including intracellular signal transduction, gene expression, cellular organelle function, axonal transport and synaptic plasticity [6-11]. In addition, recent studies have shown that virtually every proteolytic fragment of APP, including the secreted ectodomain, A $\beta$, C99 and AICD, can differentially modulate calcium signaling [12], and even lead to intracellular calcium dyshomeostasis [13,14].

Capacitive calcium entry (CCE) is a store depletion-activated calcium influx pathway [15], through which calcium enters the cells via store-operated calcium channels (SOCs) on the plasma membrane, replenishing ER calcium stores [13]. CCE was first identified as a major route of calcium influx in non-excitable cells, but is now known to be present in smooth muscle cells, neurons and other excitable cells as well [16-19]. CCE prolongs the duration of intracellular $\mathrm{Ca}^{2+}$ elevation and assists in refilling depleted ER 
$\mathrm{Ca}^{2+}$ stores [20]. As a major mechanism of cellular $\mathrm{Ca}^{2+}$ signaling, CCE has been implicated in a number of neuropathological conditions, including AD [19]. It has been reported that knockout of presenilins (PS1 and PS2) alters ER calcium stores [21]. In addition, their corresponding familial $\mathrm{AD}$ mutations act as negative regulators of CCE, which might contribute to the onset of dementia [22-24].

In contrast to extensive studies on the relationship between presenilins and CCE, the roles of full-length APP and its proteolytic derivatives on $\mathrm{CCE}$ regulation remain to be elucidated. We therefore investigated the regulatory effects of APP on CCE. Time-lapse recordings of intracellular $\mathrm{Ca}^{2+}$ signals were performed in both neural $2 \mathrm{a}(\mathrm{N} 2 \mathrm{a})$ cells and mouse embryonic fibroblast (MEF) cells. N2a cells stably expressing wild-type human APP695 (APPwt) and APP gene knockout MEF cells $\left(\mathrm{APP}^{-/-}\right.$) were used here to assess the effects of APP on CCE modulation. Our results demonstrate that CCE in N2a APPwt cells is lower than in N2a wild-type (WT) cells, which indicates that wild-type APP overexpression can depress CCE. Moreover, CCE in MEF $\mathrm{APP}^{-/-}$cells was elevated compared with control cells, further supporting a negative modulatory role of APP in the CCE pathway. To examine whether the inhibitory effect of APP on CCE was mediated by the full-length protein and/or its fragments, we performed genetic and pharmacological manipulations on $\mathrm{N} 2 \mathrm{a}$ cells. In accordance with results previously published by our group [25], abrogation of $A \beta$ resulted in a further suppression of CCE in N2a APPwt cells, implying its potentiating effect on CCE. Cell culture medium treatment experiments revealed that the extracellular soluble APP fragments were unable to depress CCE. Compared with these fragments, CCE was significantly lower in N2a cells transfected with C-terminal APP fragments, suggesting that fragments anchored to the cell membrane might be responsible for the CCE suppressing effect.

\section{Materials and methods}

\subsection{Antibodies and chemicals}

Mouse monoclonal antibody 6E10, recognizing APP, was obtained from Signet Laboratory (USA). Antibody 4G8 against $A \beta$ and rabbit polyclonal antibody recognizing the C-terminal of APP were from Sigma (USA). Goat antimouse IgG and goat anti-rabbit IgG, conjugated with alkaline phosphatase, as well as $N$-[N-(3,5-difluorophenacetyl)L-alanyl]-S-phenylglycine $t$-butyl ester (DAPT) were from Sigma. G418 was from Amresco (USA).

\subsection{Cell cultures and transfection}

The cells and vectors, including mouse neural 2a (N2a) cells stably expressing wild-type human APP695 (APPwt), Swedish mutant of APP (APPswe), and their wild-type (WT) controls, i.e. blank vector-transfected N2a cells, were gen- erous gifts from Dr. Huaxi $\mathrm{Xu}$ in the Burnham Institute, USA [25]. The cell culture medium for these cells contained equal parts of DMEM (Gibco, USA) and Opti-MEM (Gibco), as well as $5 \%$ fetal bovine serum (FBS) and $0.1 \%$ penicillin \& streptomycin. Embryonic fibroblasts isolated from APP knockout mice $\left(\mathrm{APP}^{-/-}\right)$and their wild-type counterparts $\left(\mathrm{APP}^{+/+}\right)$were cultured in DMEM containing $10 \%$ FBS and $0.1 \%$ penicillin \& streptomycin [8]. Transfection of C99 was performed using lipofectamine 2000 reagent (Invitrogen, USA). The transfected cells were screened with $300 \mu \mathrm{g} / \mathrm{mL} \mathrm{G} 418$ for more than $10 \mathrm{~d}$.

\subsection{Calcium imaging}

Intracellular $\left[\mathrm{Ca}^{2+}\right]$ measurements were performed using the indicator Fluo3/AM (Calbiochem, USA). Fluo3/AM was solubilized in DMSO, aliquoted and stored at $-20^{\circ} \mathrm{C}$. Cells were loaded with $5 \mu \mathrm{mol} / \mathrm{L}$ Fluo3/AM in HBSS (145 $\mathrm{mmol} / \mathrm{L} \mathrm{NaCl}, 2.5 \mathrm{mmol} / \mathrm{L} \mathrm{KCl}, 1 \mathrm{mmol} / \mathrm{L} \mathrm{MgCl}_{2}, 20$ mmol/L HEPES, $10 \mathrm{mmol} / \mathrm{L}$ Glucose, $50 \mu \mathrm{mol} / \mathrm{L}$ EGTA) containing bovine serum albumin $(1 \%)$ at $37^{\circ} \mathrm{C}$ for $30 \mathrm{~min}$. After 30 min of washing, they were viewed using an upright microscope (BX61, Olympus, Japan). Fluorescence intensities were acquired at 3-s intervals. Digital images were collected using a CCD camera (CoolSNAP HQ, Photometrics, USA) with a $20 \times$ water immersion objective, and subsequently analyzed using MetaMorph (Molecular Devices, USA). Each experiment was performed on at least four cultures. Experiments were performed at room temperature.

\subsection{Western blotting analysis}

Cultured cells were collected and treated with cell lysis buffer. A commercially available BCA kit (Pierce, USA) was used to determine protein concentrations. Samples containing similar amounts of protein were diluted with $4 \times$ SDS-PAGE loading buffer and boiled at $100^{\circ} \mathrm{C}$ for $5 \mathrm{~min}$. After separation by $10 \%$ SDS-PAGE, the protein samples were electrophoretically transferred onto a piece of nitrocellulose membrane. Primary antibodies, 6E10 (1:1000 dilution) or C-terminal APP antibody (1:1000 dilution), were then incubated with the membrane at $4^{\circ} \mathrm{C}$ overnight. Immunoreactive bands on the membrane were then detected by incubating with alkaline phosphatase conjugated goatanti-mouse IgG (1:10000 dilution) or goat-anti-rabbit IgG (1:5000 dilution). For C99 detection, Tris-Tricine SDSPAGE was performed. Most of the procedures were the same as SDS-PAGE, except that for Tris-Tricine SDSPAGE, the samples were diluted with $4 \times$ Tris-Tricine SDSPAGE sample buffer and proteins were separated using $20 \%$ Tris-Tricine gels.

\subsection{Reverse transcription PCR}

Total RNA was extracted from cells using the Trizol RNA 
extraction reagent (Invitrogen). First-strand cDNA was synthesized from $2 \mu \mathrm{g}$ of total RNA in a final volume of 20 $\mu \mathrm{L}$ using a first-strand cDNA synthesis kit (Toyoba, Japan). PCR reaction was conducted using $3 \mu \mathrm{L}$ aliquots of the RT reaction and specific primers for TRPC1-7, TRPV6 and STIM1 mouse sequences [26,27]. Forward and reverse primers were as follows: TRPC1, 5'-CAAGATTTTGGGAAATTTCTGG-3' and 5'-TTTATCCTCATGATTTGCTAT-3'; TRPC2， 5'-GACGACATGATCCGGTTCATGTTC-3' and 5'-CTCGATCTTCTGGAAGGAGTTGGTG-3'; TRPC3, 5'GTGGGCAATAATACTCCTAA-3' and 5'-CATGACCGCCTAGCTTAA-3'; TRPC4, 5'-TCTGCAGATATCTCTGGGAAGGATG-3' and 5'-AAGCTTTGTTCGAGCAAATTTCCATTC3'; TRPC5, 5'-ATCTACTGCCTAGTACTACTGGCT-3' and 5'-CAGCATGATCGGCAATGAGCTG-3'; TRPC6, 5'-AAAGATATCTTCAAATTCATGGTC-3' and 5'-CACGTCCGCATCATCCTCAATTTC-3'; TRPC7, 5'GACTACTTCTGCAAGTGCAATGAGTGC-3' and 5'-TTCCACAAGTGTAGCACGTACTCCC-3'; TRPV6, 5'-ATCCGCCGCTATGCACA-3' and 5'-AGTTTTTCTCCTGAATCTTTTTCCAA-3'; STIM1， 5'-AGACATTTATGGCGTTGAA-3' and 5'-GAAAGGAAGGGAGGTGAA-3'. PCR was performed using Expand High Fidelity Taq polymerase (Promega, USA). Thermocycling consisted of 35 cycles of denaturation at $94^{\circ} \mathrm{C}$ for $45 \mathrm{~s}$, annealing at 53 to $62^{\circ} \mathrm{C}$ (optimized for each fragment amplified) for $45 \mathrm{~s}$ and extension at $72^{\circ} \mathrm{C}$ for $15 \mathrm{~s}$, followed by a final extension at $72^{\circ} \mathrm{C}$ for $10 \mathrm{~min}$.

\subsection{SAPP $\beta$ ELISA}

sAPP $\beta$ levels in the media of N2a APPwt and N2a APPswe cells were assessed using a sandwich enzyme-linked immunosorbent assay (ELISA) kit (Covance, USA). Briefly, $50 \mu \mathrm{L}$ of concentrated cell culture medium or standard controls from the kit were added to microtiter plates covered with primary antibody at $4{ }^{\circ} \mathrm{C}$ overnight. Secondary antibody conjugated with HRP was then applied and incubated for another $1 \mathrm{~h}$ at room temperature. After washing, the wells were loaded with chemiluminescence substrate solution. The plate was then read immediately with a luminometer.

\subsection{Statistical analysis}

Data were presented as mean $\pm \mathrm{SD}$. Student's $t$-test was used to perform statistical analysis of the results. $P<0.05$ was considered significant.

\section{Results}

\subsection{Wild-type APP overexpression attenuates CCE}

CCE was measured in N2a WT cells in parallel with N2a cells stably expressing wild-type human APP (APPwt) (Figure 1(a)). To induce CCE, cells were first incubated in
$\mathrm{Ca}^{2+}$-free medium containing cyclopiazonic acid (CPA) to deplete $\mathrm{ER} \mathrm{Ca}^{2+}$ stores, and subsequently replenished with $\mathrm{Ca}^{2+}$-containing medium $(1.8 \mathrm{mmol} / \mathrm{L})$ to facilitate calcium entry [22-24]. Figure 1(b) shows intracellular calcium changes in two representative experiments carried out with N2a WT (continuous trace) and APPwt (dashed trace) cells. The average peak amplitude of CCE, expressed as normalized ratio above baseline, was significantly decreased in N2a APPwt cells compared with N2a WT cells (Figure 1(c)), implying that wild-type APP, and/or some of its fragments, might depress CCE.

$\mathrm{CCE}$ in the APP gene knockout MEF cells $\left(\mathrm{APP}^{-/-}\right)$was also compared with that in wild-type MEF cells $\left(\mathrm{APP}^{+/+}\right)$. Significantly greater CCE was found in MEF $\mathrm{APP}^{-/-}$cells compared with MEF $\mathrm{APP}^{+/+}$control cells (Figure 1(d),(e)). This suggests that CCE is apparently enhanced by the absence of APP, indicating that APP might be necessary to maintain CCE at normal levels. Since APP can be processed by secretases to produce several fragments in addition to full-length APP, levels of APP fragments may also be elevated in N2a APPwt cells, and down-regulated in MEF $\mathrm{APP}^{-/-}$cells. These results suggest that full-length APP and/or its fragments have the ability to suppress CCE.

\subsection{Abrogation of $A \beta$ further depresses $C C E$ in N2a APPwt cells}

The suppression of CCE in N2a APPwt cells could be mediated by full-length APP and/or its fragments. To discriminate between these possibilities, N2a cells were manipulated with gene transfection or pharmacological treatments before CCE assessments. As mentioned above, our previous results demonstrated that $A \beta$ can potentiate CCE in $\mathrm{N} 2 \mathrm{a}$ cells stably expressing Swedish mutant APP (APPswe) [25]. This finding has been bolstered by the results obtained in N2a APPwt cells here. A $\beta$ antibody 4G8, which can completely block the effect of extracellular $A \beta$, was added to the culture medium of N2a APPwt cells for $24 \mathrm{~h}$ (at $0.05 \%, \mathrm{v} / \mathrm{v}$ ). Following this treatment, CCE in N2a APPwt cells was further depressed compared with N2a APPwt controls not treated with 4G8 (Figure 2(a),(b)). Furthermore, a $24 \mathrm{~h}$ incubation of N2a APPwt cells with $2 \mu \mathrm{mol} / \mathrm{L}$ DAPT, which can inhibit $\gamma$-secretase activity and therefore stop the secretion of $A \beta$, had a similar effect on CCE (Figure 2(c)-(e)). Abrogation of $A \beta$ in N2a APPwt cells resulted in a further attenuation of CCE compared with either N2a WT or APPwt control cells (Figure 2(b),(e)). Given the CEE-enhancing effect of $A \beta$, we propose that full-length APP and/or its proteolytic derivatives other than $A \beta$ might mediate the depression of CCE, with a more powerful impact.

\subsection{Membrane-anchored APP fragments depress CCE}

APP can be processed by $\beta$-secretase or $\alpha$-secretase, releasing large soluble fragments, sAPP $\beta$ and $\operatorname{sAPP} \alpha$, into the 

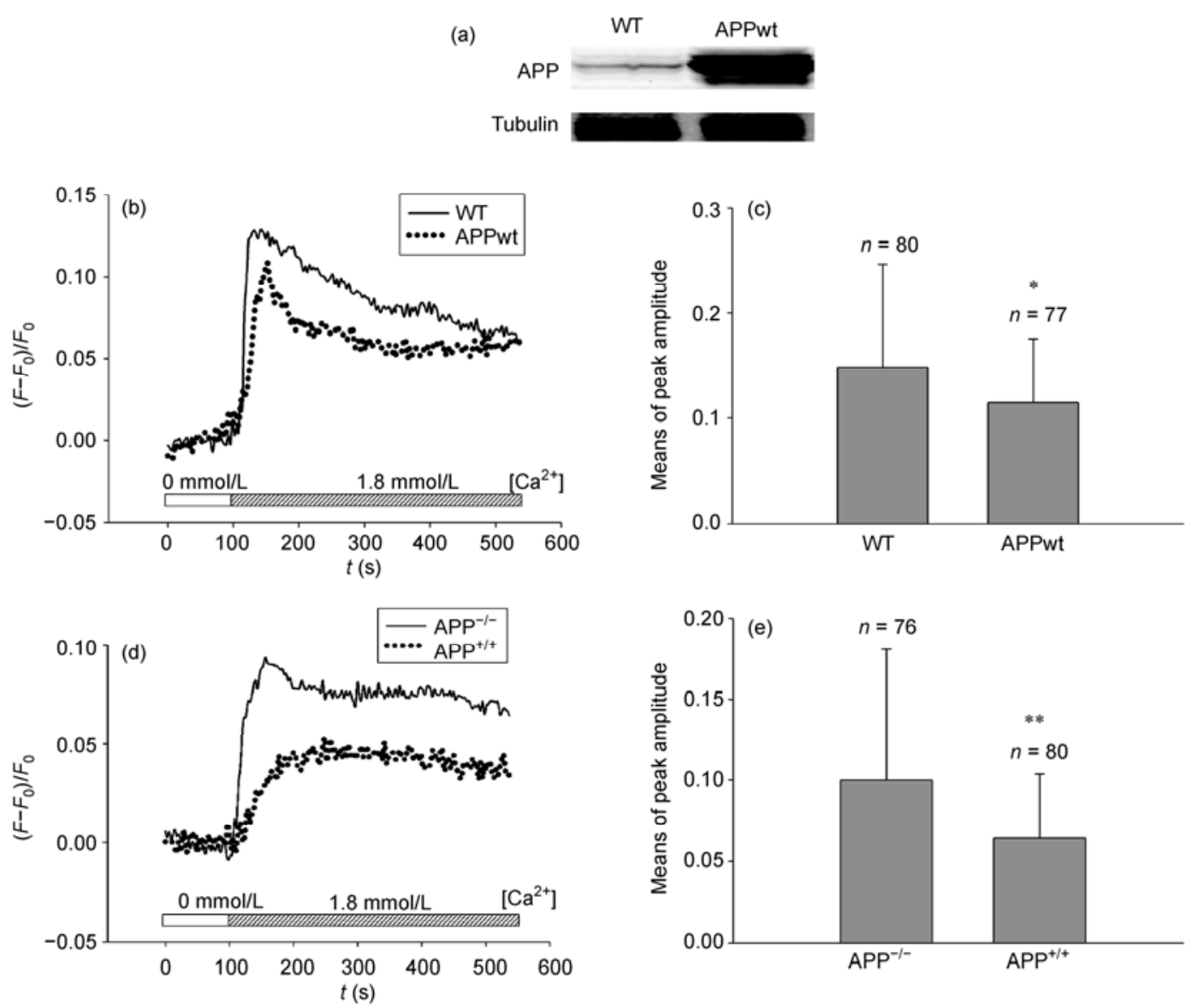

Figure 1 CCE in N2a APPwt cells was lower than in N2a WT controls. (a) APP expression levels were higher in N2a APPwt cells than in WT cells. Cell lysates from different cells were analyzed by Western blotting with anti-APP monoclonal antibody (6E10) (upper panel); (b) representative time courses of CCE in N2a WT and APPwt cells; (c) the average peak amplitudes of CCE in N2a WT and APPwt cells; (d) representative time courses of CCE in APP knockout MEF cells $\left(\mathrm{APP}^{-/}\right)$and wild-type MEF cells $\left(\mathrm{APP}^{+/+}\right)$; (e) the average peak amplitudes of CCE in MEF $\mathrm{APP}^{-/-}$and $\mathrm{APP}^{+/+}$cells. $n$, number of cells; $* P<0.05, * * P<0.01$.

extracellular space. To determine if these secreted fragments are involved in the depression of CCE in N2a APPwt cells, we performed a number of experiments. Culture media were collected from N2a APPswe cells, which mainly contain SAPP $\beta$, after a 24-h incubation period, as well as from N2a APPwt cells, which mainly produce sAPP $\alpha$ (Figure 3(a)). N2a WT cells were then incubated with culture medium from N2a APPswe or APPwt cells, separately, in the presence of $0.1 \%$ mouse anti-A $\beta$ antibody $4 \mathrm{G} 8$ to abrogate the effect of $A \beta$. After $24 \mathrm{~h}, \mathrm{CCE}$ was measured in both of these N2a WT cultures. No obvious changes in CCE were observed in N2a WT cells when they were incubated with these media containing different quantities of sAPP $\alpha$ and sAPP $\beta$ (Figure 3(b),(c)), suggesting that the secreted fragments of APP may not participate in CCE depression in N2a APPwt cells.

The effect of the membrane-anchored APP fragments on CCE was then studied in N2a cells. To examine the role of C-terminal APP fragments in the regulation of CCE, N2a cells were transfected with a $\mathrm{C} 99$ construct $\left(\mathrm{APP}_{\mathrm{CTF}}\right)$ or an empty vector control before CCE measurements. The 300 $\mu \mathrm{g} / \mathrm{mL}$ G418 was used to screen the cell lines for a period greater than $10 \mathrm{~d}$. Western blotting analysis showed that both C99 and C83 were overexpressed in the cell line (Figure 3(d)). Before CCE estimation, N2a APP treated with $2 \mu \mathrm{mol} / \mathrm{L}$ DAPT for $24 \mathrm{~h}$ to exclude the influence of $\mathrm{A} \beta$ or AICD fragments generated endogenously. The average peak amplitude of CCE was found to be dramatically attenuated in N2a APP $\mathrm{CTF}_{\text {C }}$ cells (Figure 3(e),(f)). These results demonstrate an important role of $\mathrm{C}$-terminal APP fragments, C99 and/or C83, in CCE depression.

\subsection{CCE depression in N2a APPwt cells is independent of the transcription of store-operated calcium channels (SOCs)}

To clarify the mechanism underlying the depressed CCE in N2a APPwt cells, we examined the expression of SOCs in N2a APPwt and WT cells. RT-PCR was used to measure transcription of the SOCs recently identified in animal cells [26,27], including TRPC 1-7, TRPV 6 and STIM1. Four of these were found to be transcribed in both N2a WT and APPwt cells (Figure 4(a)). However, none showed remarkable differences at the mRNA level between N2a APPwt 

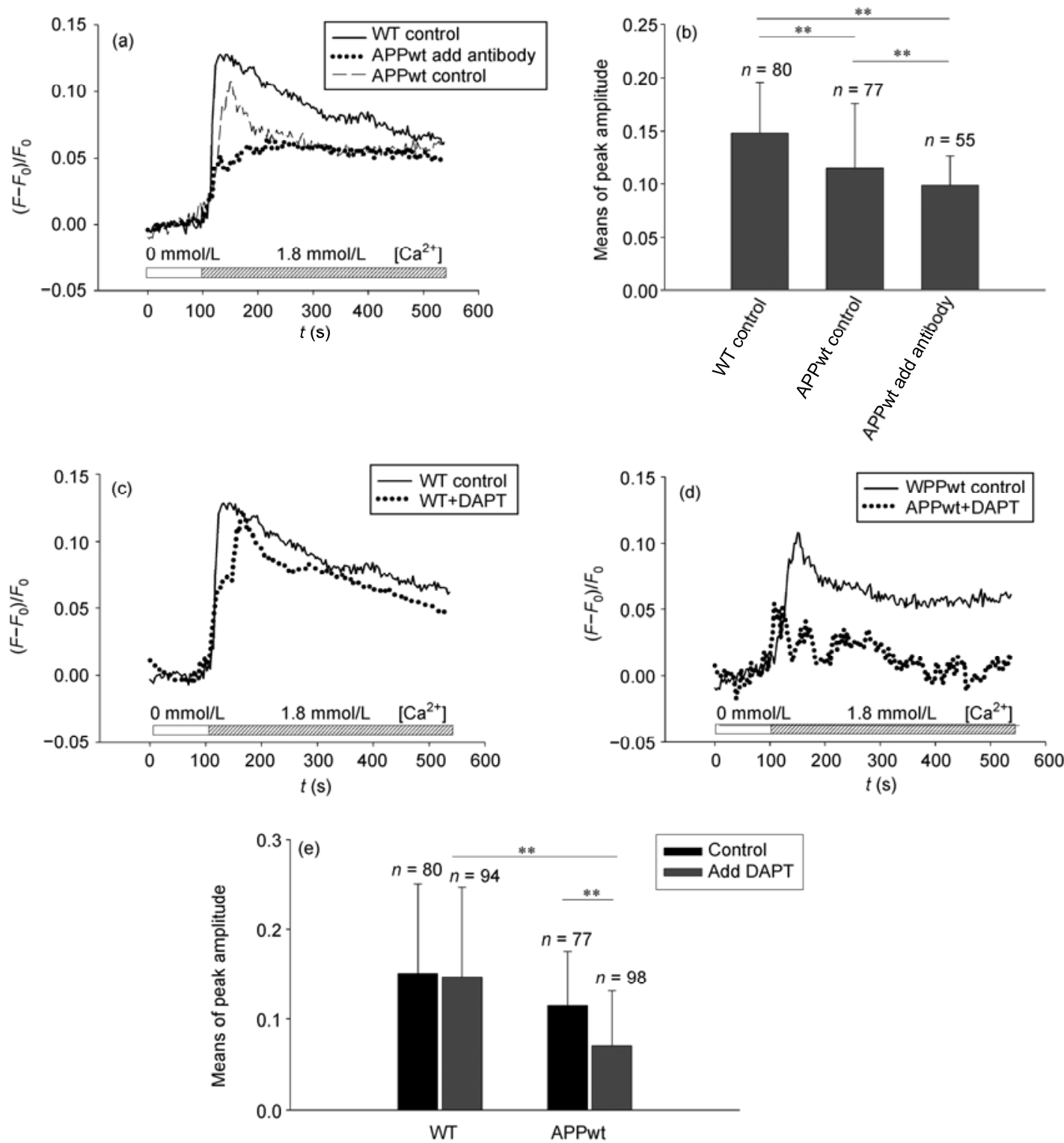

Figure 2 Removal of A $\beta$ further depresses CCE. (a) Representative time courses of CCE in N2a WT cells and APPwt cells with or without A $\beta$ antibody treatment; (b) the average peak amplitudes of CCE in N2a WT and APPwt cells with or without A $\beta$ antibody treatment; (c) representative time courses of CCE in N2a WT cells with or without DAPT treatment; (d) representative time courses of CCE in N2a APPwt cells with or without DAPT treatment; (e) the average peak amplitudes of CCE in N2a WT and APPwt cells with or without DAPT treatment. $n$, number of cells; **P $<0.01$.

and WT cells (Figure 4(b)). This suggests that transcriptional regulation of store-operated channels is not involved in the mechanism by which the APP C-terminal fragments depress CCE.

\section{Discussion}

APP, a type I intrinsic membrane protein, is widely expressed and distributed in the central nervous system and peripheral tissues [28]. While the roles of APP mutations in the pathogenesis of $\mathrm{AD}$ have been thoroughly studied, the normal physiological functions of the protein remain unclear and debatable [29,30]. Recently published reports highlight the importance of APP in various cellular processes, ranging from intracellular signal transduction to synaptic plasticity $[6,11]$. APP can be processed by $\alpha-, \beta-$ and $\gamma$-secretases to generate various proteolytic products, including secreted APPs, AICD and A $\beta$. The effects of some of these APP proteolytic derivatives on cellular calcium homeostasis have been studied $[13,14]$. However, whether APP proteins and/or its fragments regulate CCE remains to be clarified. CCE is one of the primary mechanisms regulating calcium influx into the cytoplasm. It regulates a number of vital cellular processes, such as gene transcription, cell cycle regulation, apoptosis and calcium oscillation [15,18,31]. Disturbed CCE signaling has been found to play a role in the neurodegenerative process 
(a)
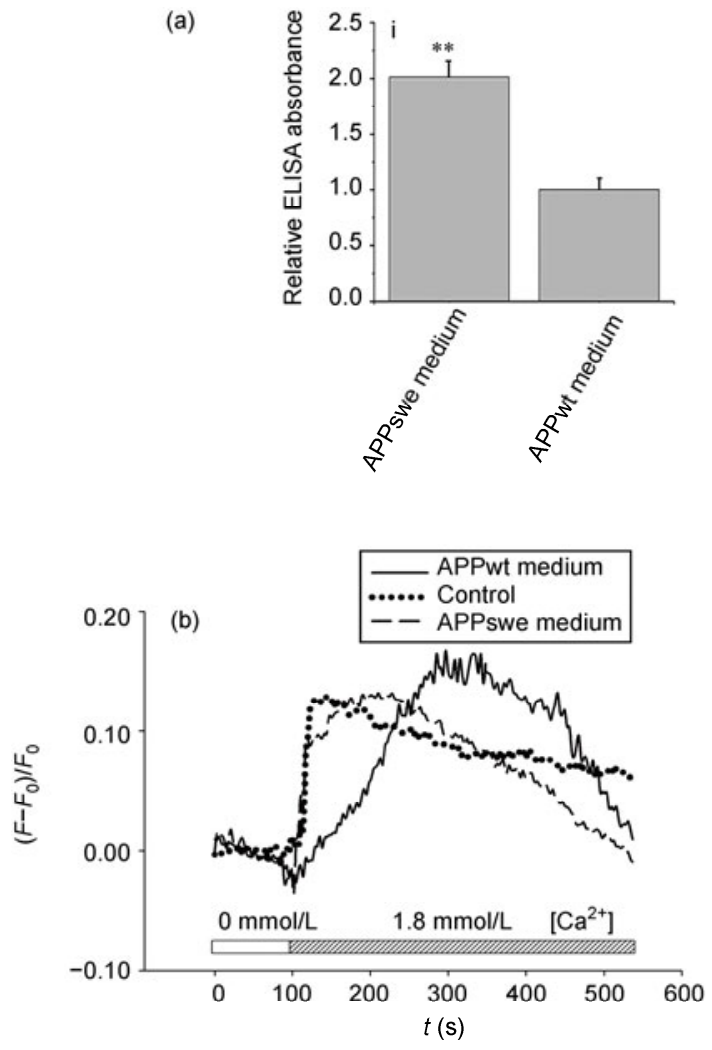

(d) $\quad \mathrm{APP}_{\mathrm{CTF}} \quad \mathrm{WT}$

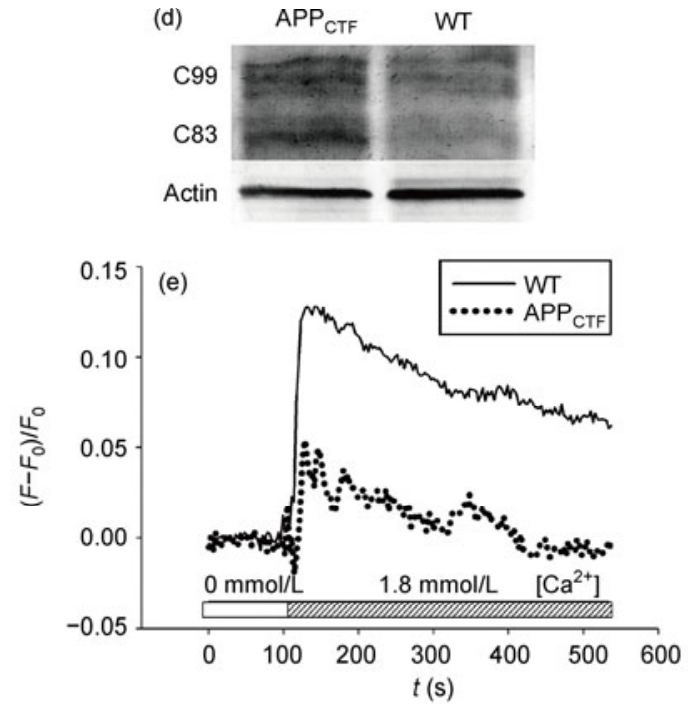

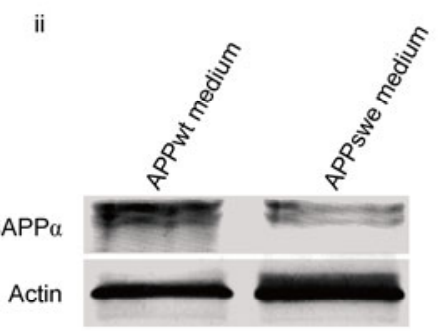
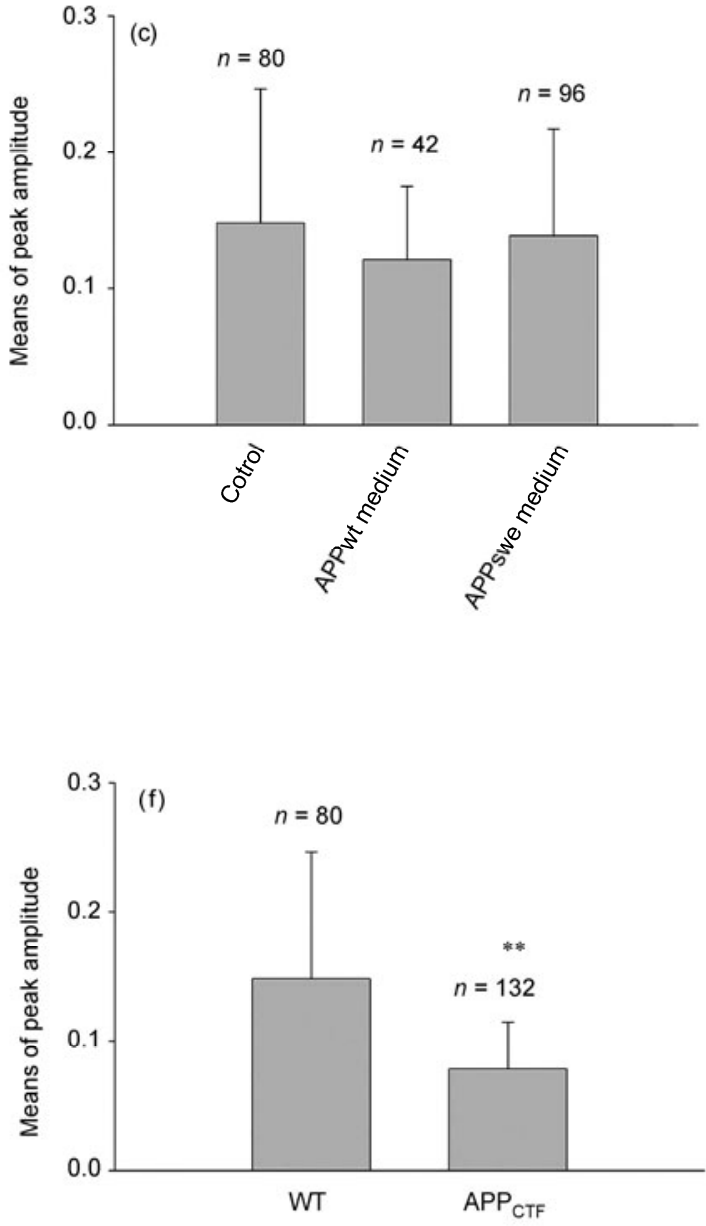

Figure 3 The effects of secreted and C-terminal fragments of APP on CCE. (a) Relative contents of sAPP $\beta$ and sAPP $\alpha$ in the media of N2a APPwt and APPswe cells. Media from different cell cultures were collected and analyzed by ELISA to detect sAPP $\beta$ (i, $n=3$ ) and by western blotting with antibody $6 \mathrm{E} 10$ to detect sAPP $\alpha$ (ii, which is representative of three independent experiments); (b) representative time courses of CCE in N2a WT cells treated with N2a APPwt or APPswe medium; (c) the average peak amplitudes of CCE in N2a WT cells treated with N2a APPwt or APPswe cell culture medium; (d) APP-CTF fragment expression levels were higher in N2a cells transfected with the C-terminal APP construct $\left(\mathrm{APP}_{\mathrm{CTF}}\right)$. Cell lysates from different cells were analyzed by western blotting with a C-terminal APP-specific antibody; (e) representative time courses of CCE in N2a WT and APP ${ }_{\mathrm{CTF}}$ cells; (f) the average peak amplitudes of CCE in N2a WT and $\mathrm{APP}_{\mathrm{CTF}}$ cells. $n$, number of cells; $* * P<0.01$.

underlying $\mathrm{AD}[22-24]$.

In this study, we investigated the effect of APP on CCE. We found that wild-type human APP overexpression can depress CCE. This finding may provide substantial insight into the physiological functions of APP. However, a study by Herms et al., which focused on the modulatory role of mutant presenilin-1 on CCE, implied that APP knockout does not significantly change CCE [23], which is not in agreement with our findings. This discrepancy could be because of differences in experimental protocols and/or the 
(a)

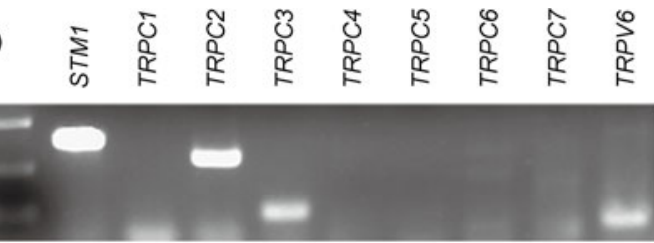

(b)

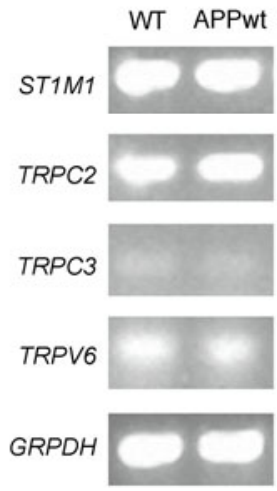

Figure 4 APP does not affect mRNA levels of store-operated calcium channels. (a) mRNA expression levels of representative store-operated calcium channels in N2a WT cells determined using RT-PCR; (b) mRNA expression levels of four store-operated calcium channels in N2a WT and APPwt cells.

model cells used.

As APP is processed by secretases to produce several fragments, the CCE depressing effect of wild-type APP observed here could be the combined effect of full-length APP and/or its fragments. The effects of APP fragments on CCE were therefore investigated here. We have already demonstrated the CCE-potentiating effect of $\mathrm{A} \beta$, the most toxic fragment of APP [25,32]. CCE in N2a APPwt cells could be further depressed by treatment with $A \beta$ antibody or DAPT, suggesting that full-length APP and/or APP fragments other than $\mathrm{A} \beta$ can depress CCE in N2a APPwt cells, and this depressing effect is even stronger than the CCEpotentiating effect of $\mathrm{A} \beta$.

The extracellular secreted fragments of APP have been demonstrated to exhibit neuroprotective properties, such as preventing tau hyperphosphorylation, protecting against oxidative impairment and enhancing memory [12,33,34]. They might attenuate the calcium response to protect hippocampal neurons from excitotoxicity caused by cellular insults, such as $A \beta$ or excessive glutamate $[35,36]$. Secreted APPs may also protect cells with PS1 mutations by stabilizing intracellular calcium levels [37]. However, we failed to find any significant effect of these secreted APPs on CCE response (it is worth noting that the initial rate of CCE in N2a WT cells treated with APPwt medium was somewhat lower than in N2a WT controls despite the unchanged average peak amplitude; this observation requires further study for clarification). These results prompted us to investigate the action of C-terminal APP fragments on CCE in N2a cells by transfecting them with C99 constructs. C99 transfection induced a lower CCE compared with control cells. As C99 fragments are the obligatory precursors of $A \beta$ peptides, the cleavage of $\mathrm{C} 99$ fragments by $\gamma$-secretase was inhibited using DAPT before CCE measurement. Therefore, it appeared that C99 fragments mediated the observed alterations in CCE signaling. Since C99 can be cleaved by $\alpha$-secretase to generate C 83 fragments, both C99 and C83 are overexpressed in $\mathrm{N} 2 \mathrm{a} \mathrm{APP}_{\mathrm{CTF}}$ cells. We were therefore unable to determine whether $\mathrm{C} 99$ or $\mathrm{C} 83$, or both, contribute to the depression of CCE in $\mathrm{N} 2 \mathrm{a} \mathrm{APP}_{\mathrm{CTF}}$ cells.

The mechanisms of CCE regulation are complex [38]. Our recently published data indicate that there is no significant difference in ER calcium store content between N2a APPwt and WT control cells [39]. Therefore, other mechanisms must be responsible for the modulation of CCE by C-terminal APP fragments. One of these might be altered expression of store-operated channels. To examine this possibility, we examined the transcriptional levels of several SOCs in N2a WT and APPwt cells. Among the SOCs expressed in both N2a WT and APPwt cells, we failed to find any obvious differences in mRNA expression between these two cell lines. Thus, the inhibitory action of C-terminal APP fragments on CCE is likely to be caused by an alternative mechanism. Further studies are required to clarify the molecular mechanisms underlying this modulation in detail.

This work was supported by the State Key Laboratory of Biomembrane and Membrane Biotechnology, the National Natural Science Foundation of China (NSFC)/Research Grants Council of Hong Kong (RGC) Joint Research Scheme (81161160570), and Tsinghua-Yue-Yuen Medical Sciences Fund (20240000514).

1 Reita C, Brayne C, Mayeux R. Epidemiology of Alzheimer disease. Nat Rev Neurol, 2011, 7: 137-152

2 Zhang F, Geng H Y. What can false memory tell us about memory impairments in Alzheimer's disease? Chin Sci Bull, 2010, 55: 3989-3997

3 Chow V W, Mattson M P, Wong P C, et al. An overview of APP processing enzymes and products. Neuromolecular Med, 2010, 12: $1-12$

4 Cole S L, Vassar R. The role of amyloid precursor protein processing by BACE1, the $\beta$-secretase, in Alzheimer disease pathophysiology. J Biol Chem, 2008, 283: 29621-29625

5 Reddy P H. Amyloid precursor protein-mediated free radicals and oxidative damage: Implications for the development and progression of Alzheimer's disease. J Neurochem, 2006, 96: 1-13

6 Karelson E, Fernaeus S, Reis K, et al. Stimulation of G-proteins in human control and Alzheimer's disease brain by FAD mutants of APP (714-723): Implication of oxidative mechanisms. J Neurosci Res, 2005, 79: 368-374

7 Cao X, Sudhof T C. A transcriptively active complex of APP with Fe65 and histone acetyltransferase Tip60. Science, 2001, 293: $115-120$

8 Sheng B Y, Niu Y, Zhou H, et al. The mitochondrial function was impaired in APP knockout mouse embryo fibroblast cells. Chin Sci Bull, 2009, 54: 1725-1731

9 Kamal A, Stokin G B, Yang Z, et al. Axonal transport of amyloid precursor protein is mediated by direct binding to the kinesin light chain subunit of kinesin-I. Neuron, 2000, 28: 449-459

10 Stokin G B, Goldstein L S. Axonal transport and Alzheimer's disease. Annu Rev Biochem, 2006, 75: 607-627

11 Torroja L, Packard M, Gorczyca M, et al. The Drosophila $\beta$-amyloid 
precursor protein homolog promotes synapse differentiation at the neuromuscular junction. J Neurosci, 1999, 19: 7793-7803

12 Mattson M P, Guo Z H, Geiger J D. Secreted form of amyloid precursor protein enhances basal glucose and glutamate transport and protects against oxidative impairment of glucose and glutamate transport in synaptosomes by a cyclic GMP-mediated mechanism. J Neurochem, 1999, 73: 532-537

13 LaFerla F M. Calcium dyshomeostasis and intracellular signalling in Alzheimer's disease. Nat Rev Neurosci, 2002, 3: 862-872

14 Bojarski L, Herms J, Kuznicki J. Calcium dysregulation in Alzheimer's disease. Neurochem Int, 2008, 52: 621-633

15 Parekh A B, Putney J W. Store-operated calcium channels. Physiol Rev, 2005, 85: 757-810

16 Albert A P, Saleh S N, Peppiatt-Wildman C M, et al. Multiple activation mechanisms of store-operated TRPC channels in smooth muscle cells. J Physiol, 2007, 583: 25-36

17 Bouron A. Activation of a capacitative $\mathrm{Ca}^{2+}$ entry pathway by store depletion in cultured hippocampal neurons. FEBS Lett, 2000, 470: 269-272

18 Putney J W. Capacitative calcium entry in the nervous system. Cell Calcium, 2003, 34: 339-344

19 Usachev Y M, Thayer S A. $\mathrm{Ca}^{2+}$ influx in resting rat sensory neurones that regulates and is regulated by ryanodine-sensitive $\mathrm{Ca}^{2+}$ stores. J Physiol, 1999, 519: 115-130

20 Fanger C M, Hoth M, Crabtree G R, et al. Characterization of T-cell mutants with defects in capacitative calcium entry-genetic evidence for the physiological roles of CRAC channels. J Cell Biol, 1995, 131: 655-667

21 Kasri N N, Kocks S L, Verbert L, et al. Up-regulation of inositol 1,4,5-trisphosphate receptor type 1 is responsible for a decreased endoplasmic-reticulum $\mathrm{Ca}^{2+}$ content in presenilin double knock-out cells. Cell Calcium, 2006, 40: 41-51

22 Leissring M A, Akbari Y, Fanger C M, et al. Capacitative calcium entry deficits and elevated luminal calcium content in mutant presenilin-1 knockin mice. J Cell Biol, 2000, 149: 793-798

23 Herms J, Schneider I, Dewachter I, et al. Capacitive calcium entry is directly attenuated by mutant presenilin-1, independent of the expression of the amyloid precursor protein. J Biol Chem, 2003, 278: 2484-2489

24 Yoo A S, Cheng I, Chung S, et al. Presenilin-mediated modulation of capacitative calcium entry. Neuron, 2000, 27: 561-572

25 Niu Y, Su Z, Zhao C, et al. Effect of amyloid $\beta$ on capacitive calcium entry in neural 2a cells. Brain Res Bull, 2009, 78: 152-157

26 Garcia R L, Schilling W P. Differential expression of mammalian
TRP homologues across tissues and cell lines. Biochem Biophys Res Commun, 1997, 239: 279-283

27 Okada T, Inoue R, Yamazaki K, et al. Molecular and functional characterization of a novel mouse transient receptor potential protein homologue TRP7. $\mathrm{Ca}^{2+}$-permeable cation channel that is constitutively activated and enhanced by stimulation of $\mathrm{G}$ Protein-coupled receptor. J Biol Chem, 1999, 274: 27359-27370

28 Thinakaran G, Koo E H. Amyloid precursor protein trafficking, processing, and function. J Biol Chem, 2008, 283: 29615-29619

29 Hardy J. The amyloid hypothesis for Alzheimer's disease: A critical reappraisal. J Neurochem, 2009, 110: 1129-1134

30 Senechal Y, Larmet Y, Dev K K. Unraveling in vivo functions of amyloid precursor protein: Insights from knockout and knockdown studies. Neurodegener Dis, 2006, 3: 134-147

31 Zhao Y, Liu X L, Zhang Y, et al. Modulation of synchronous calcium oscillations in hippocampal neurons by photostimulation of astrocytes with femtosecond laser. Chin Sci Bull, 2010, 55: 3436-3440

32 Niu Y, Sheng B Y, Song B, et al. Endogenously generated amyloid $\beta$ increases membrane fluidity in neural 2a cells. Chin Sci Bull, 2009, 54: 394-398

33 Han P, Dou F, Li F, et al. Suppression of cyclin-dependent kinase 5 activation by amyloid precursor protein: A novel excitoprotective mechanism involving modulation of tau phosphorylation. J Neurosci, 2005, 25: 11542-11552

34 Meziane H, Dodart J C, Mathis C, et al. Memory-enhancing effects of secreted forms of the $\beta$-amyloid precursor protein in normal and amnestic mice. Proc Natl Acad Sci USA, 1998, 95: 12683-12688

35 Mattson M P. Secreted forms of $\beta$-amyloid precursor protein modulate dendrite outgrowth and calcium responses to glutamate in cultured embryonic hippocampal neurons. J Neurobiol, 1994, 25: 439450

36 Goodman Y, Mattson M P. Secreted forms of $\beta$-amyloid precursor protein protect hippocampal neurons against amyloid $\beta$-peptideinduced oxidative injury. Exp Neurol, 1994, 128: 1-12

37 Guo Q, Robinson N, Mattson M P. Secreted $\beta$-amyloid precursor protein counteracts the proapoptotic action of mutant presenilin-1 by activation of NF-kappaB and stabilization of calcium homeostasis. J Biol Chem, 1998, 273: 12341-12351

38 Targos B, Baranoska J, Pomorski P. Store-operated calcium entry in physiology and pathology of mammalian cells. Acta Biochim Pol, 2005, 52: 379-409

39 Ma T, Gong K, Yan Y, et al. Mitochondrial modulation of storeoperated $\mathrm{Ca}^{2+}$ entry in model cells of Alzheimer's disease. Biochem Biophys Res Commun, 2012, 426: 196-202

Open Access This article is distributed under the terms of the Creative Commons Attribution License which permits any use, distribution, and reproduction in any medium, provided the original author(s) and source are credited. 